\title{
An Analysis of the Figures of Speech in Mental Spaces: A Cognitive Semantic Study
}

\author{
Nabaz Ismael Hamad \\ Prof. Dr. Suhayla Hameed Majeed \\ Asst Prof. Dr. Wirya Ezzaddin Ali \\ Department of English Language \\ College of Languages \\ Salahaddin University \\ Iraq
}

\begin{abstract}
This study is an attempt to investigate a range of the figures of speech within Mental Spaces Theory to provide a counter argument that dramatic language can equally be examined with reference to linguistic structures just like everyday language. The study also makes the counter claim that the figures of speech should have value outside literature, as they are not only literary tools in literature. The study is conducted in a qualitative method by taking a series of examples of from Shaw's 'Man and Superman' to be analysed under cognitive semantic theory of Mental Spaces. The study has concluded that the figures of speech are primarily linguistic tools for meaning construction, and from there these devices are expanded from their linguistic function to also fulfill the literary ones. From a cognitive perspective, it has been realised that these literary devices enable the language users to firstly conceptually construct meaning in mind via spaces creation and connection that comprise information as their elements, and then these information are verbally realised in communication.
\end{abstract}

Keywords: cognitive, mental spaces, meaning construction, dramatic discourse.

\section{Theoretical Background}

\subsection{Overview}

Mental Spaces are, according to Fauconnier's (1997:11) definition, "partial structures that proliferate when we think and talk, allowing a fine-grained partitioning of our discourse and knowledge structures". These Mental Spaces contain elements which designate discourse entities, and theydepend on the more stable domains from which they recruit information for 'on-line' meaning construction. 'Meaning' is consequently divided into discrete, temporary conceptual 'packets' that are built 'on-line' for purposes of local understanding of narratives, metaphors, speech acts and "general reasoning" (Fauconnier, 1997:5). In cognitive semantics and mental spaces theory in particular, meaning construction is treated as a process that is essentially conceptual in nature. From this angle, linguistic expressions do not have stable meanings themselves, rather they work like 'partial building instructions' for the construction of complex but temporary conceptual domains, gathered as a result of ongoing discourse. These conceptual domains are the mental spaces that can be connected to one another in numerous ways. The connection of these mental spaces enables the interlocutors to move back and forth in the ongoing discourse. Thus, meaning is absent in the linguistic items themselves, but arises from the dynamic process of building and connecting mental spaces, known as conceptualisation. Figures of Speech refer to any specific, deliberate constructions or choices of language which an author uses to convey meaning in a particular way. An author's use of a literary devices usually occurs with a single word or phrase, or a particular group of words or phrases, at one single point in a text (Braiman, 2007: 1).Van Peer and Hakemulder (2006: 546-8) state that figure of speech arethe literary devices as a collection of universal artistic structures that are so typical of all works of literature frequently employed by the writers to construct meanings and a logical framework to their works through language. When such works are read by readers, they ultimately recognize and appreciate them. Because these devices do not only beautify the piece of literature but also give deeper meanings to it. 


\subsection{Statement of the Problem}

The first and foremost problem is that it has always been fully called for among linguists, researchers and literary works that literary dramatic language and natural language represent two somewhat different registers. Hence, they are by no means subjected to be treated via the same route of analysis. Another primary problem is that dramatic discourse is argued to have utilized, as meaning construction devices, some special figures of speech that are called meaning devices which are purely literary devices and have little or even no values outside literature. It has been widely claimed that the dramatic language is difficult and not easily analyzable in terms of its linguistic structures. One more problem is that it is generally denied that play writers such as Shaw put more care into the language aspects than the literary sides in the establishment of the plays. The last, but not the least, problem is that in pedagogical process the linguistic aspects, devices and elements are considered to be the least relevant areas in meaning construction, scene construing and meaning conception during teaching, analysing and comprehending the plays.

\subsection{Hypotheses}

It is firstly hypothesised that meaning construction takes place conceptually in mind via spaces creation and connection first, and then verbalized and communicated orally. That leads to the second hypothesis which is that conceptual meaning construction and meaning conception are not only pervasive in spoken form, but also in written form, particularly in dramatic language. Then, since literary devices are typical structures used to convey different messages, give meanings and logical framework through language, it is hypothised that these literary devices are not only literary tools, but, if not rather, at least equally, are cognitive semantic tools in meaning construction and conception. This is because these devices are essentially used to construct meaning and conceptualizing it, and then from there they are extended to fulfill literary functions too.

\subsection{Data Collection and Selection}

The study is a cognitive semantics qualitative analysis to one of Bernard Shaw's plays. The data collected for the analyses of the study are represented by one of the most semantically rich works of Shaw, 'Man and Superman'. The playis accurately read to locate the areas, parts, structures, expressions, devices and elements that match the needs of the study. For the analyses and examinations, one of the most recent cognitive semantic theories is applied that is Fauconnier's (1985/ 1994) model of Mental Space Theory. The main factor lies behind selecting this theory is the truism that it is among the latest theories of cognitive semantics and the most interesting one in terms of meaning construction. A series of literary devices such as Foreshadowing, Flashback, Pun, Analogy, Metaphor, Metonymy and Simile are taken to be analysed within Mental Spaces Theory. For doing so, sufficient amount of samples are taken from the play to suit the needs of the study and verify the analysis and discussions of the study. From a linguistics-semantic perspective, the taken samples are examined under the light of the Mental Space Theory components, and then they are combined to the figures of speech to account for the literary side. This is done so through the play to demonstrate how these literary devices are at the heart of the two cognitive semantic theories in meaning construction of human language. Lastly, most of the analyses are accompanied by figures in a way mental spaces theory does in all explanations, and for more clarity of the highly abstract entities.

\section{The Application of Mental Spaces Theory in the Figure of Speech Analysis.}

\subsection{Foreshadowing in Mental Spaces}

Foreshadowing gives the audience, reader hints or signs about the future. It suggests what is to come through imagery, language, and/or symbolism. It does not directly give away the outcome, but rather, suggests it (Shen, 2007: 169). Within mental space theory, we argue that foreshadowing can also be indirect indication among the interlocutors for something that will happen later. In their utterances meaning construction and conception, the interlocutors build future spaces based on their current base space, as in:

(1) a. ANN. [earnestly] Take care, Jack. You may make Tavy very happy if you mislead him about me.

(Man and Superman, p. 53)

b. ANN. Take care, Jack: if anyone comes while we are like this, you will have to marry me.

(Man and Superman, p. 231)

c. Tanner. If we two stood now on the edge of a precipice, I would hold you tight and jump.

(Man and Superman, p. 231) 
In all these examples Ann and Tanner are talking about their relationship and its future. In (1a), firstly, Ann tells Tanner when you misinform Octavius about me, you make him happy, because if Octavius increases his love to me, and later I do not marry him and his sorrows become more. Therefore, you make Octavius happy if he is convinced that marriage is meaningless and I am not suitable to him, so that Octavius reduces his concern and affection to me and when I get married to you he will be fine. Secondly, by the use of the 'take care' phrase, Ann means Tanner that I am planning to marry you, not Octavius. Thirdly, Ann tells Tanner that you make Octavius happy by keeping him away from marriage and from me, but you take care of yourself since I marry you, so what do you do for yourself?. Fourthly, Ann tells Tanner when I marry you, Octavius becomes happy because he realises that all what you say about me and Octavius's marriage finally backfires to you. All in all, the above interpretations plus the pragmatic and discourse context assistance indicate that Ann and Tanner's marriage is upcoming. In that communication, the audiences, readers and even including the listener are all pre-informed about the coming event 'marriage'. Putting this in mental spaces theory frame, Ann opens a future space ' $F$ ' based on the base space ' $\mathrm{B}$ '. In the future space ' $F$ ', Ann is married to Tanner, this future space is built and projected from the base space 'B', which is Ann's present communication to Tanner, as presented in the below figure.

\section{Base space}

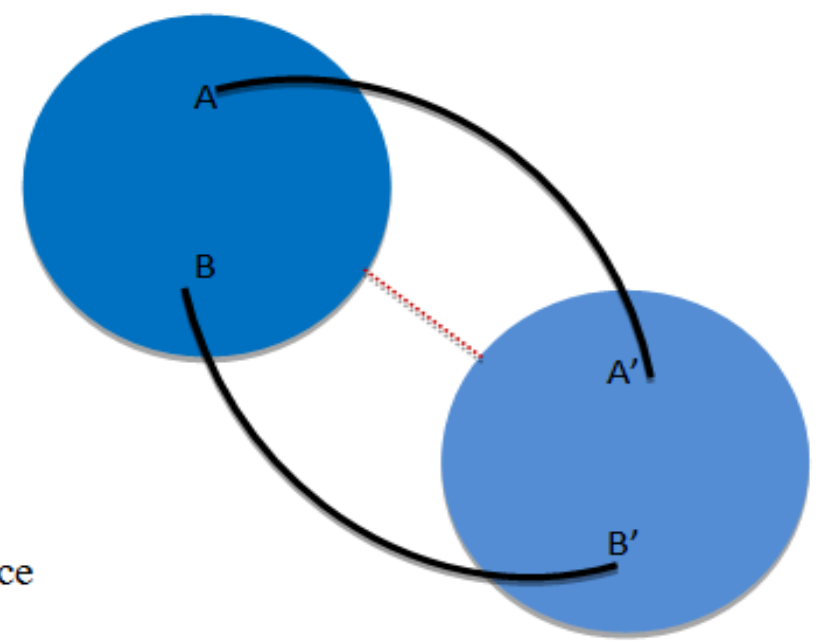

Future space

Figure 2.1.Illustrates foreshadowing is building the future space

As the discourse progresses in the play, in (1b) this time Ann more directly tells Tanner to get married. Here, Ann uses the same phrase 'take care' to hint the audiences, readers and the listener 'Tanner' that the marriage between her and Tanner will happen. In mental spaces terms, in this example again via foreshadowing Ann builds future space ' $F$ ' projected from the base space 'B'. In example (1a), Tanner stays on the base space as the focused space, unlike Ann who wants to make future space focused. This is due to only having communication as relation between $a$ and $b$ in the ' $\mathrm{B}$ ' space. This time in (1b), Tanner is more responsive to mentally move to the future space ' $F$ ' and make it the focused space because of having a strong relationship as the relation between a and $b$ in ' $\mathrm{B}$ ' space. Accordingly, his answer is 'If we two stood now on the edge of a precipice, I would hold you tight and jump' in (1c). That indicates his readiness for the marriage even if the marriage is like jumping of high cliff, it also means he is ready to hold her close and tight her even for jumping off a cliff he will not let her go away. In this way, the marriage foreshadowing is emphasized by Ann in (1b) and re-emphasized by Tanner in (1c). Sentence ( $1 \mathrm{~b}$ and $\mathrm{c})$ shown in the below figure where the stronger connection between the two spaces presented by a thicker dotted line and the focus on the future space is presented by a dark colour of the space. 


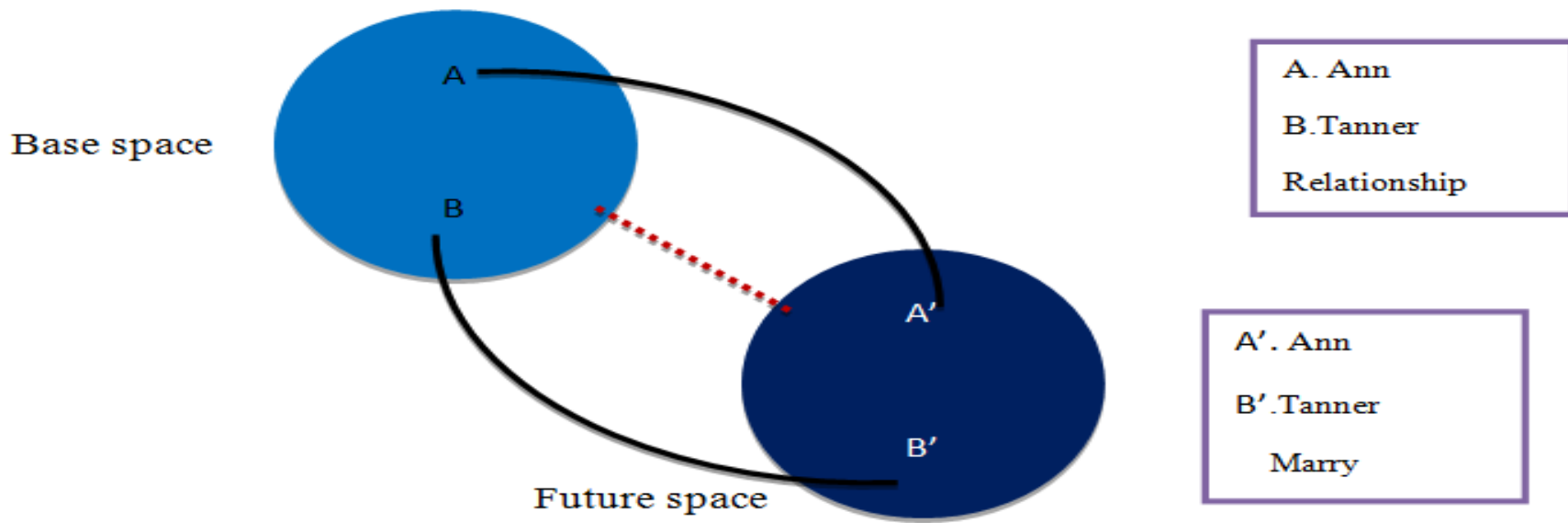

Figure 2.2.Illustrates foreshadowing is building the future

The foreshadowings made by the future mental spaces show that the love and marriage ideas were initiated by Ann and her efforts continued despite Tanner's avoidance and her attempts ended up with Tanner's approval and inclination for marriage too.

\subsection{Flashback in Mental Spaces}

Flashback is a device that moves an audience from the present moment in a chronological discourse or narrative to a situation or scene in the past. Often, flashbacks are abrupt interjections that further explain a story or character with background information and memories (Pavis, 1998: 151). Flashback with reference to mental spaces theory is a shift of focus via the Access Principle from the on-line space backwards to some other already built spaces in lattice of the discourse, as in:

(2) A. ANN... But isn't that only natural, Jack? We have known each other since we were children. Do you remember?

Tanner. [abruptly breaking loose] Stop! I remember everything.

ANN. Oh, I daresay we were often very silly; but-

Tanner. I won't have it, Ann. I am no more that schoolboy now than I am the dotard of ninety I shall grow into if I live long enough. It is over: let me forget it.

(Man and Superman, p. 42)

B. Tanner. Are you sure it was not that we were beginning to be something more? What does the beginning of manhood and womanhood mean in most people's mouths? You know: it means the beginning of love. But love began long before that for me. Love played its part in the earliest dreams and follies and romances I can remember, may I say the earliest follies and romances we can remember? though we did not understand it at the time.

(Man and Superman, p. 47)

C. Tanner....My soul was born of that passion.

ANN. I noticed that you got more sense. You were a dreadfully destructive boy before that.

Tanner. Destructive! Stuff! I was only mischievous.(Man and Superman, p. 48)

In these examples Tanner and Ann are talking to each other about their feelings, behaviours and comprehension of things in now and in the past. Both interlocutors talk about their relationship, feelings and understanding each other at the present time, but they shift from present by referring to their past when Ann says 'since we were children do you remember?' from there Tanner begins going back by saying 'I remember..., that schoolboy...', and then he goes to a further past by saying 'the earliest dreams...'. After that, he goes to the furthest past, which is his birth, by saying 'my soul was born...' . In relation to mental spaces theory, Tanner and Ann's understanding for the things is in the on-line space ' $\mathrm{B}$ '. From that on-line space they gradually move backwards to the past that are already existing spaces in their life, such as remembering childhood and schoolboy past space termed 'P1', then to the earliest dreams past space termed 'P2', later to the birth that is the utmost past termed 'P3', as shown in figure 2.3 


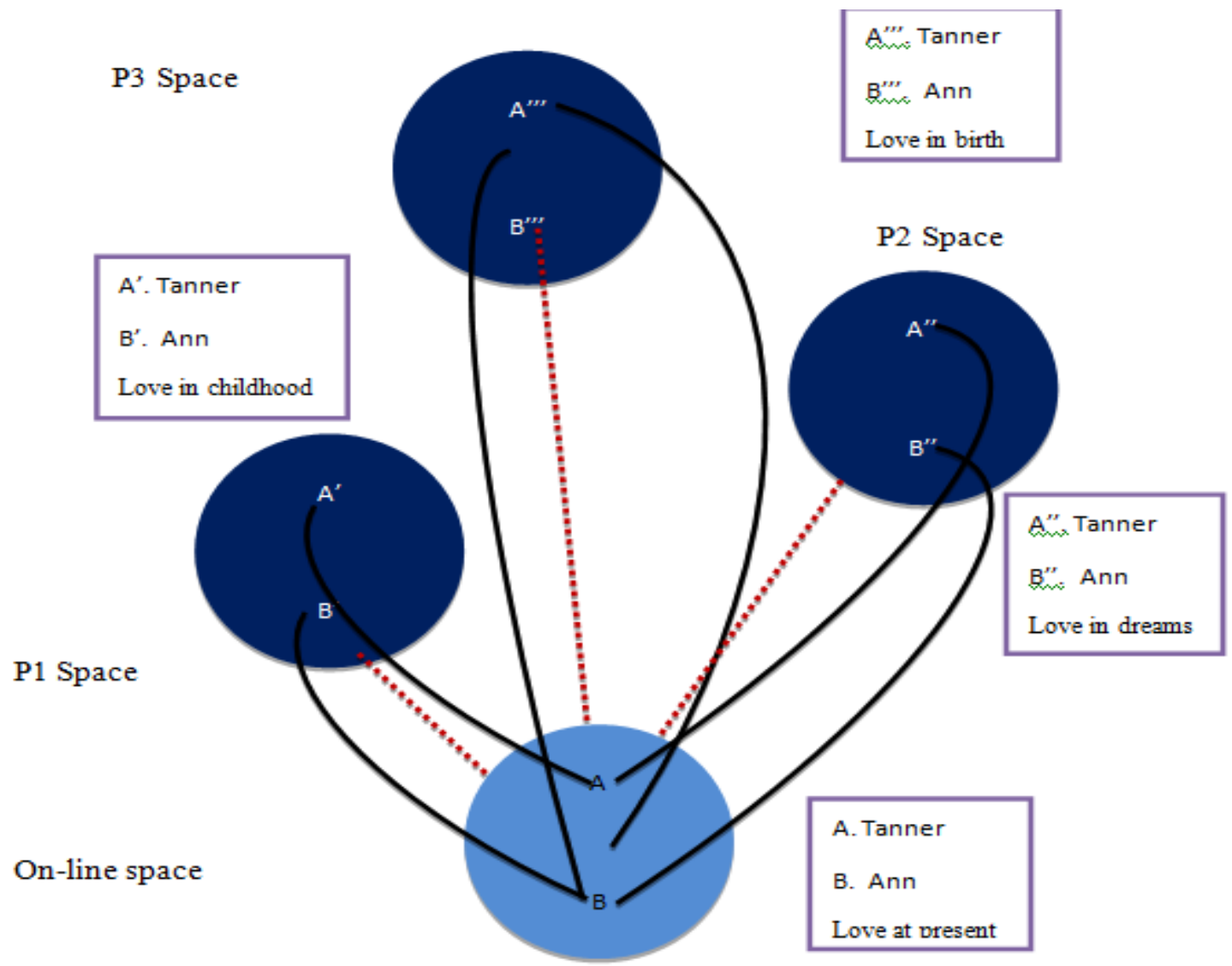

Figure 2.3. Illustrates flashback is moving backwards to pre-existing spaces

As shown in figure 3 by dark spaces, the main reason of going back to past is that the characters connect their present to past and make the past mental space in focus for themselves, audience and readers. Further, the characters would like to reveal that both had an early passion to love, marriage and to each other as they have it now, as if they have naturally pursued the chosen and the correct path. In other words, if they love each other now and get married is something driven by destiny and they are designed so.

\subsection{Pun in Mental Spaces}

In literature, pun is a literary devices achieved via the use of those words that easily suggest more than one meaning, or those words that have different meanings but sound the same. Pun is used to add humor and giving audience and readers a confusion moment to figure out the intended meaning (Pollack, 2012: xxiii). Linguistically, puns are often based on polysemy and homophones. Within mental spaces theory, it is not only the audience and readers who face double meanings with pun words, but the interlocutors too, when they deliberately avoid specifying the intended referent for one another. Puns can also make readers and interlocutors pause and consider what they have read or heard from a different angle. Shaw's Man and Superman is loaded with the word 'man' often used as a pun among the characters to convey more than a meaning, as in:

(3) a. Tanner. [patting him on the back] Bear it like a man, Tavy, even if you feel it like an ass. It's the old game: she's not tired of playing with you yet. (Man and Superman, p. 71)

b. Tanner. Yes, a lifetime of happiness. If it were only the first half hour's happiness, Tavy, I would buy it for you with my last penny. But a lifetime of happiness! No man alive could bear it: it would be hell on earth.

(Man and Superman, p. 16)

In these examples Tanner is talking to Octavius about Ann and marriage in general. Tanner tells Octavius to tolerate Ann's words like a 'man'. Literary speaking, the word man suggests two meanings, the first one means as a human being, while the second one implies Octavius as young male. The presence of both meanings is confirmed by the directly subsequent complementary phrase of 'even if you feel it like an ass', it means as a 'human' not as a 'donkey' that is known for being stupid animal, and as 'young male' not as a 'young donkey'. Linguistically speaking, in mental spaces theory, this double meaning can be dealt with under roles and values relation and distinction. 
On the role reading, the word man refers to any human beings who have to bear and understand such words expressed by Ann. So, the reference 'man' points to no particular referents, and the element in the on-line mental space is open to include any human beings who fulfil that role, as shown in figure 2.4. For humour addition, Tanner tells Octavius any human beings who cannot understand Ann's aim, they are even not humans, but they fulfil the role of one of the most stupid animals such as a donkey. Thefunction of the role reading is to make Tanner's words be less direct, scornful and offensive to Octavius' affection in pursuing Ann's desire to marriage.
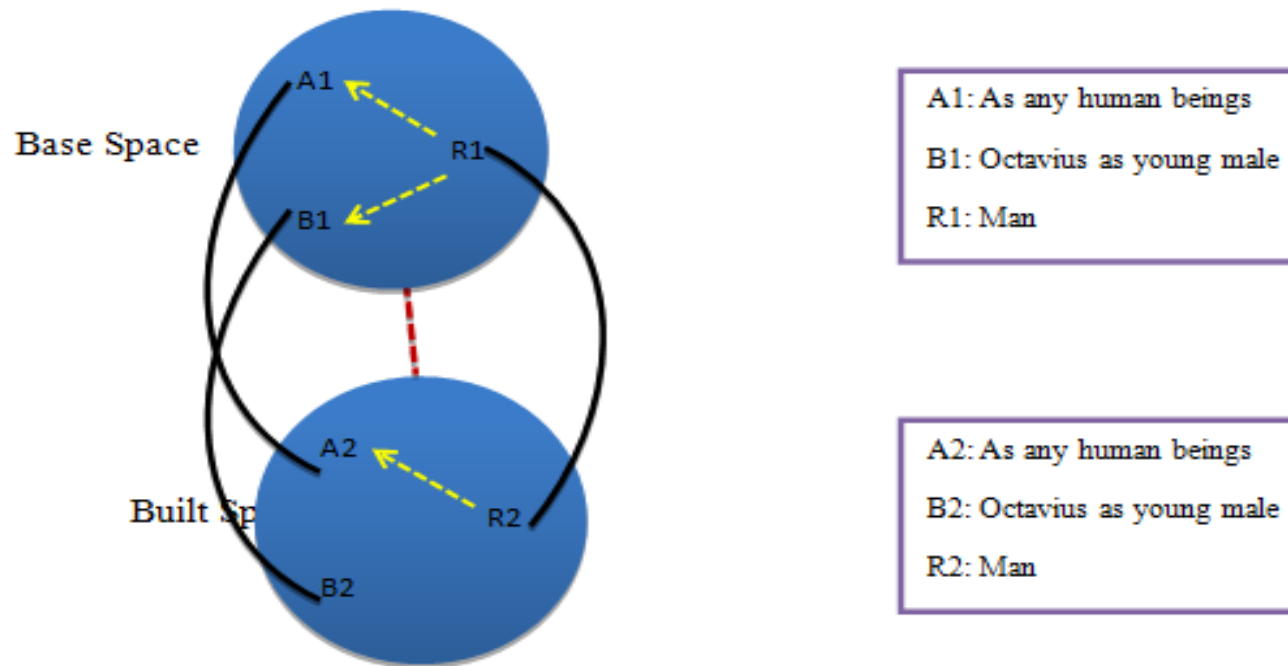

Figure 2.4.Illustrates the role reading of the pun word 'man'.

On the value reading, the reference 'man' points to a particular referent, who is Octavius as a 'young male'. In Tanner's perspective, males are superior to females in thinking and deciding. Tanner says, so Octavius if you consider yourself a young mature male, then understand Ann's means. Otherwise, you are an animal and even an immature one that 'ass'. On this value reading, the element in the on-line mental space is clearly specified by identity who is Octavius, as shown in figure 2.5. The function of the value reading is to make Tanner be more straightforward to inform Octavius about his lack of understanding of Ann's words.

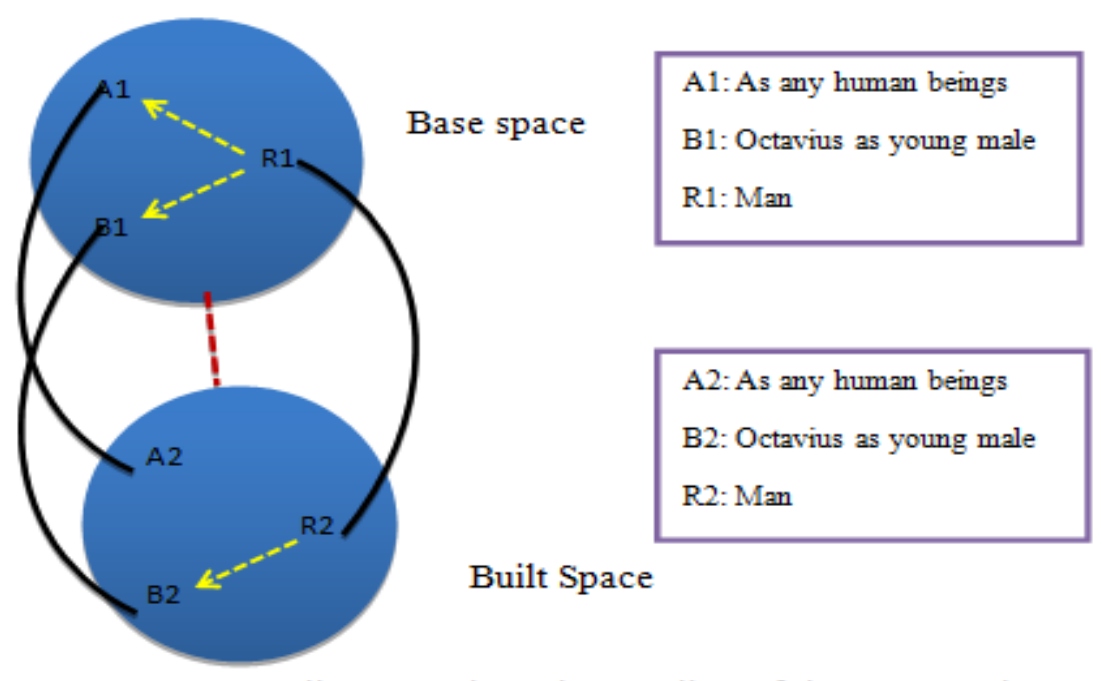

Figure 2.5.Illustrates the value reading of the pun word 'man'.

Despite adding humour to the communication, the pun via the word 'man' enables Tanner to give Octavius a couple of chances to conceptualise the meaning of his utterance. The indirect one is the role reading, and the direct one is the value reading. Such meaning construction is done to facilitate the meaning conception for Octavius, Tanner wanted to strengthen his utterance by including himself in being stupid immature animal if he believes Ann's words, as well as avoid getting reaction from Octavius. Another way to look at this is to argue that Tanner conveys two messages with his pun, the direct message is the value one and it is for the listener 'Octavius, as young male, this is where the pun accomplishes its linguistic function. 
Meanwhile, the indirect message is the role one and it is for the audiences and readers, as it includes any human beings, and this is where the pun fulfils its literary function.

\subsection{Analogy in Mental Spaces}

Analogy is a literary technique in which two unrelated objects are compared for their shared qualities. Unlike a Metaphor or a Simile, an analogy is not only a figure of speech, though the three are often quite similar. Instead, analogies are strong rhetorical devices used to make rational arguments and support ideas by showing connections and comparisons between dissimilar things (Ross, 1982). By using an analogy we can convey a new idea by using the blueprint of an old one as a basis for understanding. With a mental linkage between the two, one can create understanding regarding the new concept in a simple and succinct manner (Ross, 1970: 727-731). When it comes to cognitive semantics, Fauconnier (1997:18) states that human conceptual networks are intricately structured by analogical and metaphorical mappings, which play a key role in the synchronic construction of meaning and in its diachronic evolution. Parts of such mappings are so entrenched in everyday thought and language that we do notconsciously notices them; other parts strike us as novel and creative, as in:

(4) Ramsden. ...This man Tanner was only a boy to him: his opinions were something to be laughed at, like a man's hat on a child's head.(Man and Superman, p.9)

Here, Ramsden is talking to Octavius about Tanner's weak position in Whitefield's family. Ramsden wants to transfer Mr Whitefield's mental image about Tanner's undesirable and humorous role to Octavius. But in doing so, Ramsden needs to deal with a very high level of abstractness, which is Mr Whitefield's view concerning Tanner's funny and unwelcomed opinions to him. In cognitive semantics meaning construction, it is one of the essential claims that human mind cannot conceive of abstract entities. Human mind is so designed to be very limited in conceiving of abstract entities, and does not to conceive highly abstract entities at all. So, to communicate Mr. Whitefield's view, as a highly abstract entity, to Octavius, Ramsden has to explain it in terms of concrete entities. Thus, to construct meaning of what he is saying, via analogy Ramsden is mapping the abstract entity, Tanner's funny opinions to Mr. Whitefield, upon a concrete entity, a man's hat on a child's head. In this way, Ramsden makes his meaning be very straightforward for Octavius's meaning conception.

Yet the process is cognitively complex and consists of several nontrivial stages and transitions typical of what goes on in all other areas of the interlocutors conceptual systems. It is seen that vocabularies from the domain of age, 'man's age', size 'man's hat' and position 'man's role', are being used to talk and reason the domain of inconsideration and thoughtlessness. More specifically, there is a mapping of elements found in each space, in the base space there is a 'funny relation' $r$ hold between the elements of a 'a man's hat', and b 'child's head'. $a, b$ and $r$ have to be connected to their counterparts a' 'Mr Whitefield', $b$ ' 'Tanner' and r' 'Tanner's Laughed at opinions to Mr Whitefield' in the on-line built space through mapping which must be established cognitively between the interlocutors, as illustrated in figure 2.6.

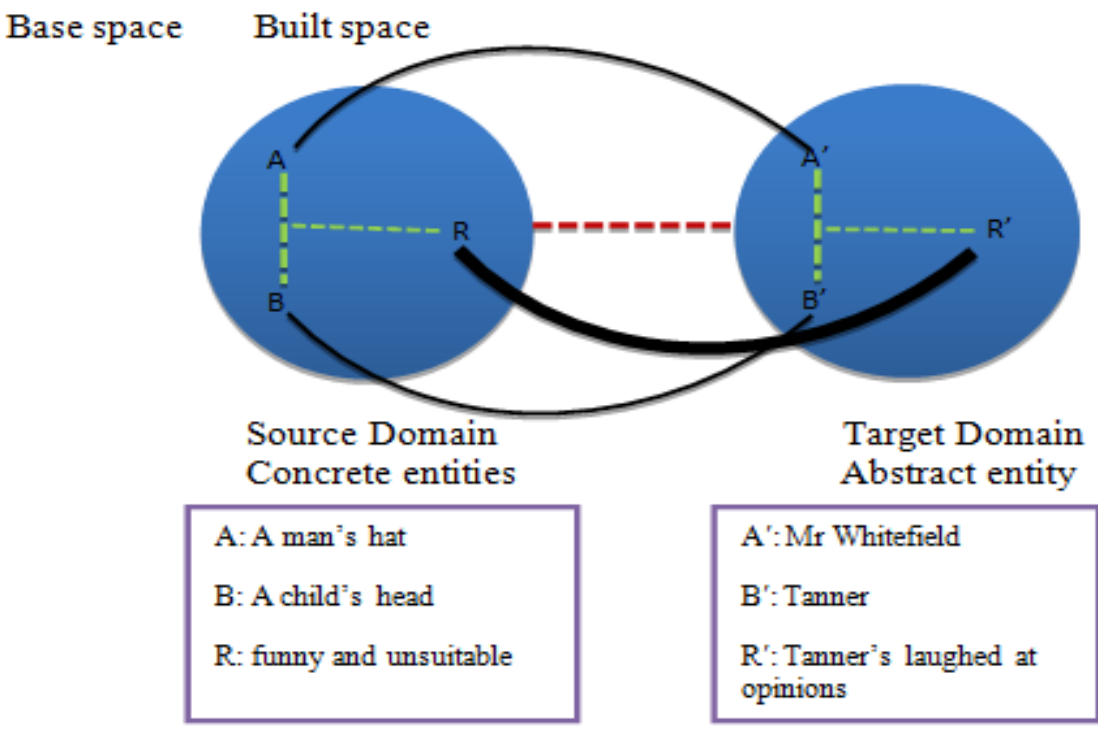

Figure 2.6. Illustrates analogical mapping between pairs of entities 
If this analogy is seen to be between similar entities, then the entities of Man's hat and the child's head in one space are similar to the entities of Mr. Whitefield and Tanner respectively in the other space. When the two mapped pairs of entities are similar to each other, the analogy provides a better way for the interlocutors to understand the more obscure entities. For instance, Mr. Whitefield's age, experience, and lack of seriousness in taking Tanner's opinions as younger and inexperienced person, by picturing it to a more common entity, Putting a man's hat on a child's head is a funny act. In this case, the mapping type becomes attribute mapping in Holyoak and Thagards' (1995) terms where there is perception or creation of similarity between the entities by the interlocutors. In Fauconnier's perspective, it is projection mapping which project part of the structure of one domain onto another and the best examples of this type are metaphors. Consequently, this type of mapping does not seem to be sufficient to the analysis here, and it is not what Ramsden wants to convey his meaning by alone. If this analogy is seen to be between two completely dissimilar pairs of entities, Man's hat and child's head pair, and Mr. Whitefield and Tanner pair. The former pair is in the base space and the latter is in on-line built space, but the relation holds between former pair, 'Man's hat on child's head' is just the same as the relation holds between the latter pair, 'Mr. Whitefield and Tanner'. Thus, the function of the analogy is to explain or describe Tanner's funny and unwanted opinions to Mr. Whitefield by examining its similarities with man's hat on a child's head. In Holyoak and Thagards' (1995) term, such an example is another type of mapping known as relational mapping, which is sensitivity to relations between entities. In in Fauconnier's terms it is Pragmatic function mappings which allows an entity to be identified in terms of its counterparts in the projection. In the type of mapping the analogy operates at a more abstract level, with relations between the entities rather than the entities themselves being highlighted or profiled. It depends on the interlocutors' ability to distinguish the similarities and dissimilarities between the entities, and yet to perceive they can have relations in common. Under the light of that type of analogy, Ramsden's analogy forces readers and his listener 'Octavius' to understand the connection between the two pairs by depending on comprehending the relation holds between each pair of entities first, and then mapping that held relation onto the relation holding between the second pair of entities.

That is why, in the figure above the line that connects the relation holds between one pair to the other is remarkably bold in mapping the two spaces. That means Ramsden tells Octavius how a man's hat on a child's head is inappropriate, funny and a kind of temporary comfort for the child. And doing so is unreal just to give the child an ease time and relief. Exactly in the same way, Mr. Whitefields' bearing to Tanner's opinions was giving temporary coziness, otherwise, in reality, Mr. Whitefield makes fun of what Tanner says. As a result, it can be argued that such an analogy is a very strong one for the mapping as it equips the interlocutors to have two mappings, projection and pragmatic function mappings and with weighing one of them, as in this example the pragmatic function mapping is weighed.

\subsection{Metaphor in Mental Spaces}

In literature, metaphor means a comparison by directly relating one thing to another unrelated thing. Unlike similes, metaphors do not use words such as "like" or "as" to make comparisons. The interlocutor relates the two unrelated things that can be similar, but are not actually the same, and the listener and audience understand that it is a comparison, not a literal equation (Foss, 2004: 249). Therefore, metaphors refer to a meaning or identity ascribed to one subject by way of another. In a metaphor, one subject is implied to be another so as to draw a comparison between their similarities and shared traits. The first subject, which is the focus of the sentences is usually compared to the second subject, which is used to convey a degree of meaning that is used to characterize the first. The purpose of using a metaphor is to take an identity or concept that we understand clearly (second subject) and use it to better understand the lesser known element (the first subject).

In cognitive semantics framework, metaphors are termed conceptual metaphors or even cognitive metaphors and were first tackled by George Lakoff and Mark Johnson in their (1980) work, and have been developed in a number of subsequent publications. The basic premise of Conceptual Metaphor is that metaphor is conceptual structure organised according to cross domain mappings or correspondences between conceptual domains. Some of these mappings are due to pre-conceptual embodied experiences, while others build on these experiences in order to form more complex conceptual structures. Here, neither the detailed background of metaphor nor its types specifically is discussed, but rather metaphor in its general sense is dealt with within mental spaces theory to argue that it is a meaning construction tool in language prior to be a figure of speech in literature, as in:

(5) Tanner. Why, man, your head is in the lioness's mouth: you are half swallowed already .

(Man and Superman, p. 29) 
In this example, Tanner is informing Octavius about Ann's ability. On a literary account, Tanner does not use literal language, which is precise and plain, in describing Ann' ability, fearlessness, bravery and eloquence in talking and trying to get married, and her superiority to man, especially Octavius. Tanner uses figurative language, which is imprecise, economic and more influential and persuasive in interaction, by comparing Ann to a lioness, particularly her mouth to a lioness's mouth. In a couple ways, Tanner is very careful in making the comparison between the unrelated entities 'Ann and lioness'. Firstly, to Tanner, no matter that she is even a lion, but it is a female one 'lioness'. Secondly, even when she is compared to lion, it does not imply that she has all the positive features of a lion, only in her mouth she is so, and lion's mouth usually stands for fear, danger, attack and so on. On a linguistic account, in relation to mental spaces, there is a conceptual mapping in Fauconnier's terms projection mapping between an entity/being 'lioness' in the base space within the source domain onto an entity/being 'Ann' in the on-line built space within the target domain. More specifically, the mapping is done via selecting a certain part 'mouth' of each entity, and then some features like 'danger and hurt' of that part are mapped from one entity 'lioness' onto the other 'Ann', as further illustrated in figure 2.7.

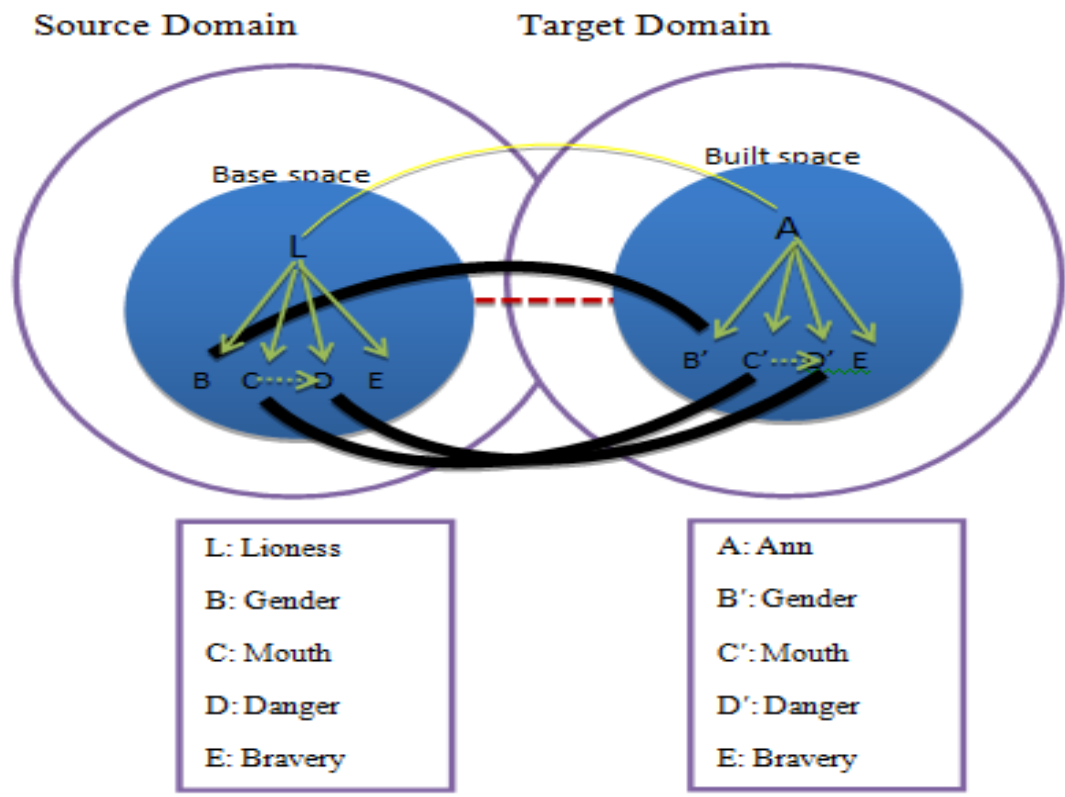

Figure 2.7. Illustrates metaphorical mapping between unrelated entities

What is also worth noticing here is that the unrelatedness of entities lioness ' $\mathrm{L}$ ' and Ann ' $\mathrm{A}$ ' themselves as shown by a thin line, and the features like bravery ' $E$ ' is not mapped from ' $L$ ' onto ' $A$ '. On the contrary, the features of gender ' $\mathrm{B}$ ', mouth ' $\mathrm{C}$ ' and danger ' $\mathrm{D}$ ' from lioness are well mapped onto ' $\mathrm{B}$ ', ' $\mathrm{C}$ ', and ' $\mathrm{D}$ ', Ann respectively, as represented by thick bold lines. What is more, in the mapping the definite article the appropriately connects the two spaces as 'the lioness' means the element in the on-line space refers back to an element 'Ann' in the preexisting space of the discourse.

\subsection{Metonymy in Mental Spaces}

Following Moulthrop (1991:120), metonymy is a literary figure of speech in which an object or concept is referred to not by its own name, but instead by the name of something closely associated with it. Metonymy and Metaphor are similar in that both are forms of figurative language that create a comparison or relationship between two different things or ideas. However, there is a difference in the nature of the relationship. Metonymy is a comparison built on the relatedness of two different things, whereas Metaphor draws a comparison between the qualities of two unrelated things. In linguistics, the idea of metonymy, alongside metaphor, as a conceptual phenomenon was first brought into discussion by Lakoff and Johnson in (1980:31) work, in which they say metonymy allows the interlocutors to conceptualise one entity by means of its relation to another. Langacker (1993:30) mentions that metonymy is a process that consists of mentally accessing one conceptual entity via another. 
Accordingly, metonymy is a reference via a conceptual entity that affords mental access to another conceptual entity 'referent'. The reference entity means the source for mentally accessing the desired target 'referent', as in:

(6) Mendoza...I am an able man, a strong man: in ten years I should have owned a first-class hotel. I met her; and you see! I am a brigand, an outcast. Even Shakespear cannot do justice to what I feel for Louisa.

(Man and Superman, 144)

Mendoza is metonymically talking to Straker and Tanner about his economic capability via referring to 'owning a first-class hotel', and love for Louisa via mentioning 'Shakespear'. In the first metonymy, he uses 'owning a firstclass hotel' to stand for richness and prosperity, specifically his richness, not literally for the building of the hotel. This is because owing a first-class hotel was, has been and will be closely related to a wealthy and happy life. Thus, Mendoza refers to a prosperous and high class life via something else intermingled with such a life and that is 'owing a first-class hotel'. This is an individual for class metonymy based on Croft and Cruse's (2004:216) listing of the relations. In the above example the structure (I should have owned...) indicates that the speaker 'Mendoza' clarifies that the state of affairs was not realised, and it is just counterfactually imagined. This counter factuality serves to show that meeting Louisa and falling in love with her reversed Mendoza's life from the possibility of prosperity to the reality of outcast. Hence, Mendoza's richness and prosperity only exists in the online hypothetical space. Mendoza uses the element of 'owing a first-class hotel' in the hypothetical on-line space as a reference to access the target in another pre-existing space, in which he has outcast life. By using the metonymy of 'owing a first-class hotel' to refer to his entire life happiness and richness, Mendoza allows the other interlocutors 'Straker and Tanner' to conceptualise what a great life he could have. And by putting the metonymy in the counterfactual structure, Mendoza allows the interlocutors to also conceptualise that in reality his current life is on the contrary to that hypothetically imagined life.

In second metonymy, there are two cognitive processes, the first is a pure metonymy where Mendoza uses the word 'Shakespear' to stand not for Shakespear himself, but for the description of love between his plays characters. This is a producer for produced metonymy that affects the thought of the interlocutors to conceptualise meaning. Here the word Shakespear exists in the on-line space and used as reference to mentally access the desired target1, namely the powerful love plays that he writes about and the ever-lasting love between the play characters is referent exists in another pre-existing space. The metonymical relatedness is shown by two blue spaces in figure 2.8. Yet there is another cognitive process when Mendoza says even Shakespeare's love plays do not suffice showing Mendoza's love for Louisa. That is analogical mapping from Shakespeare's highly descriptive and prominent love portraying between his play characters 'desired target1' in the pre-existing space onto the tremendous love between Mendoza and Louisa 'desired target2' in the base space. This analogical mapping is shown by the upper blue space and the purple space in figure 8 .

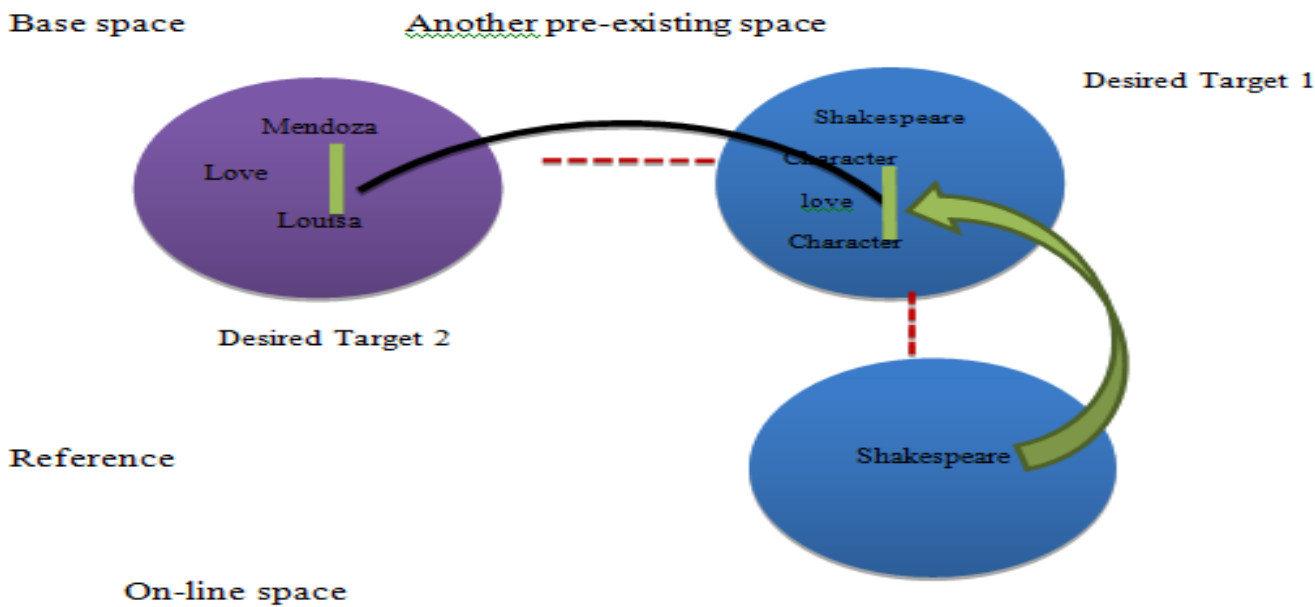

Figure 2.8. Illustrates the inclusion of metonymical relatedness and analogical mapping between reference and desired targets in lattice

In such an interaction the target concepts of Mendoza's recluse life, and the mapping from Shakespeare's description for the love between his play characters onto Mendoza's greatest everlasting love for Louisa are not namely mentioned. But they are done so via the reference entities of 'owning a first-class hotel' and 'Shakespear' that are closely associated with the target concepts. Lakoff (1987:79-89) states that metonymy is a relation between concepts, and these concepts are rounded in social, cultural, knowledge experience. 
It is due that experience that interlocutors relate two concepts and even hold part to whole relation. In literature, the part-whole relatedness is sometimes considered a different figure of speech termed synecdoche and sometimes regarded a specific type of metonymy and that latter view is preferred here. This is dues to the fact that Metonymy is more expansive, including concepts that are merely associated in meaning and not necessarily parts of the original thing or concept, while synecdocheoccurs when the name of a part is used to refer to the whole.In mental space theory, there is a cultural, historical, conceptual and experiential part-whole relationship between a certain part and its entire entity, as in:

(7) Tanner. I said the proper thing was to combine the experience of an old hand with the vitality of a young one... . (Man and Superman, p.13)

According to (Fauconnier, 1994:4-5), in a general situation in which $b$ is linked to $a$ by a pragmatic function $F$ and may be referred to by means of a description of a, according to the ID Principle. In this example, Tanner is talking to Ramsden about themselves and refers to themselves just by mentioning part of their bodies, which is 'hand'. Thus, the referent targets are 'Ramsden and Tanner' themselves respectively, via the pragmatic connector F, are pointed to by the reference triggers 'hand'. The ID Principle states that in a connected situation, a description of the triggers 'old hand' and 'new hand' can be used to identify the targets 'Ramsden's old age and old thoughts' and 'Tanner's young age and new ideas'.

\subsection{Simile in Mental Spaces}

Murfin and Ray (2003:447-8) describe simile as an explicit comparison made between two unlike things through the use of connecting words, usually 'like', 'as' or 'as...as'. The reason of making the comparison between the two unrelated entities is to indicate a common quality between them. Further, Simile is predominantly used to make an unusual thing seem more familiar or to make a familiar thing seem more unique, as in:

(8) DON JUAN. Patience, lady: you will be perfectly happy and at home here. As with the poet, "Hell is a city much like Seville."(Man and Superman, p.122)

In example (8) Don Juan is talking to the Old Woman about the awfulness of the place or specifically the city they live in. Don Juan is doing his best to make the old woman visualise hell life dreadfulness and then resemble it to the city life they live in, but the woman fails to do so, and she takes Don Juan's words rather simply and normally. Therefore, Don Juan tries in a more explicit way by using the connecting word 'like' to enable her to draw common features between hell and their city 'Seville'. There is also strengthening in the similarity between them via the quantifier word 'much'. Putting the above in mental space theory frame, Seville is an element is the online mental space and it is less familiar, unique or at least less arousing to the listener 'The Old Woman'. That is why, that element needs to be mapped onto an element in the base space 'hell' that bears close resemblances to Seville in many ways. The old woman through thinking about the entity in the base space, which is the severity of life in hell and the features such as: evilness, punishment, pain and misery, much in the same way, she can conceptualise the entity in the on-line space, which is the harshness of life and its features in Seville. This is shown in figure 9 below that the two unlike places are not connected themselves, but via the word 'like', they share common features.

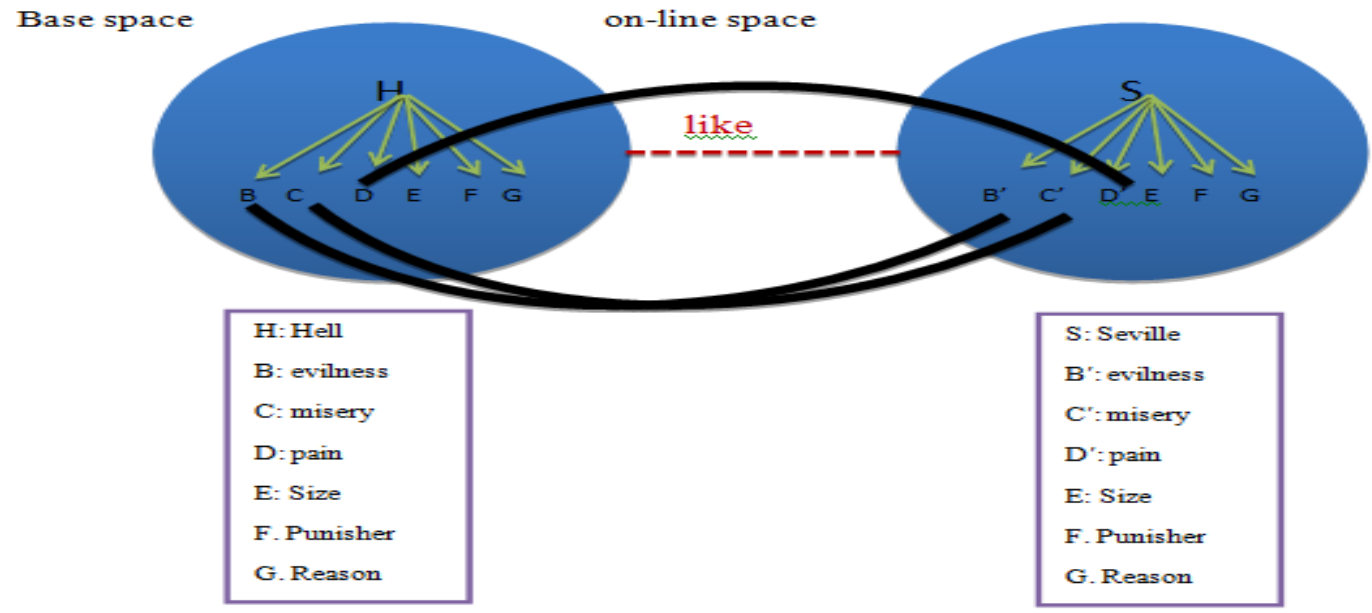

Figure 2.9. Hlustrates Simile mapping between common qualities of unrelated entities 


\section{Findings and conclusions}

Mental Spaces theory, alongside its novelty, is one the most suitable theories of cognitive semantics to investigate the figures of speech in meaning construction and conception in literary works such as drama, novel, poetry and even journalistic texts as well as everyday language due to series of reasons and outcomes as the study has arrived below:

1. Since meaning-making is a purely mental cognitive process, meaning is not present in the linguistic items themselves, they are just prompts to trigger the meaning. This claim in the theory leads to argue that in any pieces of communication in general, and in the characters' communication in the plays in particular, the interaction interlocutors are firstly mentally connected through such figures of speech and the meaning of each linguistic expression is generated there, then these meanings are being realized verbally and physically via language materials.

2. It is realised that the literary devices are not only literary tools, but, if not rather, at least equally, are cognitive semantic tools in meaning construction and conception. A range of literary devices as foreshadowing, flashback, pun, analogy, metaphor, metonymy, and simile are exemplified and analysed in terms of mental spaces theory to verify the positing that these devices are essentially used to construct meaning and conceptualizing it, and then from there they are extended to fulfill literary functions too.

3. Using pun in literary works is explained in terms of role reading and value in reading in mental spaces theory. That is to say, two messages are conveyed with his pun, the direct message is the value one and it is for the listener, this is where the pun accomplishes its linguistic function. Meanwhile, the indirect message is the role one and it is for the audiences and readers, as it includes any human beings, and this is where the pun fulfils its literary function.

4. It also concluded that in analogy it is usually the relation holds between two entities one space is mapped onto the relation hold between another couple of entities in another space, so the mapping is not between the entities themselves like in metaphor and simile.

5. Despite the resemblance, there is a difference in the mapping when comparisons are made via simile and metaphor. Simile uses the connecting words and makes an explicit comparison by asserting that two different things aresimilar. A simile sets thing A and thing B side by side to compare them. Meanwhile, metaphor is not only the absence of the connecting words, but there is assertion of an implicit comparison by stating that one thing is the other thing. Instead of setting two entities A and B side by side through the use of connecting words, metaphor superimposes them.

6. As the completion of (5), it is argued that a comparison expressed via metaphor indicates a stronger and tighter resemblance between the two entities than a comparison made by a simile. This is because in simile the mapping is a matter of being like each other, otherwise different. This implies that there is still a kind of keeping the two entities parted in other ways or other qualities. On the contrary, in metaphorthe mapping is a matter of being each other. This means that the mapping is towards the fusion of the two entities. Subsequently, metaphor is not only a matter of resemblance between A and B, like in simile, but rather A is B. So, the comparison can be more powerful, imaginative or descriptive in metaphor.

\section{References}

Braiman, Jay .(2007).Literary Devices. [Online] Available: http://www.jbraiman.com/mrbraiman/lit.htm Croft, William., \& Cruse, D. Alan .(2004).Cognitive Linguistics. Cambridge: Cambridge University Press. Fauconnier, Gilles .(1985).Mental Spaces ( $1^{\text {st }}$ ed.). Cambridge: Cambridge University. Fauconnier, Gilles .(1994).Mental Spaces (2 ${ }^{\text {nd }}$ ed.). Cambridge: Cambridge University. Fauconnier, Gilles .(1997).Mappings in Thought and Language. Cambridge: Cambridge University Press. Foss, Sonja .(2004). Rhetorical Tradition: Exploration and Practice. Long Grove III: Wayland Press. Holyoak, Keith\& Thagards, Paul .(1995).Mental Leaps: Analogy in Creative Thought. Unpublished MA thesis. Faculty of Modern and Medieval Languages. MIT. Cambridge, MA.

Lakoff, George\& Johnson, Mark .(1980). Metaphors We Live By. Chicago: University of Chicago Press.

Lakoff, George .(1987).Women, Fire, and Dangerous Things:What Categories Reveal About the Mind. Chicago and London: University of Chicago Press.

Langacker, Ronald W. (1993). Reference-point constructions. Cognitive Linguistics, 4(1), 1-38.

Moulthrop, Stuart .(1991). Reading from the map: Metonymy and metaphor in the fiction of "Forking Paths". In P. Delany and G.P. Landow (Eds.),Hypermedia and Literary Studies(pp119-132).Cambridge: MIT Press. 
Murfin, Ross; Ray, Supryia M .(2003). The Bedford Glossary of Critical and Literary Terms (2nd ed.). Bedford/St. Martins.

Pavis, Shantz .(1998). Dictionary of the Theatre: Terms, Concepts, and Analysis. Toronto; Buffalo: University of Toronto Press.

Pollack, John .(2012). The Pun Also Rises: How the Humble Pun Revolutionized Language, Changed History, and Made Wordplay More Than Some Antics. The USA: Penguin Group.

Ross, Josef F .(1970). Analogy and The Resolution of Some Cognitivity Problems. The Journal of Philosophy, 67 (20), 725-746.

Ross, Josef F .(1982). Portraying Analogy. Cambridge: Cambridge University Press.

Shen, Yeshayahu .(2007). Foregrounding in poetic discourse: between deviation and cognitive constraints. Language and Literature, 16(2), 169-181.

Van Peer, Willie. \& Jèmeljan, Hakemulder .(2006). Foregrounding. In Keith Brown (Eds.), Encyclopedia of Language and Linguistics(pp546-551). Elsevier. 